\title{
O compartilhamento de ações de estágio como espaço de formação inicial para a docência
}

\section{Bruna Corso}

brubisc@gmail.com

orcid.org/0000-0002-2751-8278

Unersidade Federal do Paraná (UFPR),

Curitiba, Paraná, Brasil

Flávia Dias de Souza flaviad@utfpr.edu.br

orcid.org/0000-0002-0586-433X

Universidade Tecnológica Federal do

Paraná (UTFPR), Curitiba, Paraná, Brasil

\section{RESUMO}

O presente artigo apresenta resultados de uma pesquisa de mestrado desenvolvida no campo da Educação Matemática, particularmente sobre o estágio na formação inicial de professores de matemática. Fundamentada na Teoria da Atividade, a investigação foi realizada por meio de pesquisa de campo com situações de acompanhamento em turmas de Estágio Curricular Supervisionado em um curso de Licenciatura em Matemática, tendo como foco os momentos de compartilhamento de ações de estágio. Nesse cenário, investigou-se possibilidades de organização do ensino pelo professor da disciplina de estágio que possam favorecer a inserção dos estudantes à docência no contexto do estágio curricular supervisionado. A pesquisa se deu à luz dos pressupostos do materialismo histórico-dialético. O processo de captação de dados se deu por meio dos diários de bordo, observações e gravações em áudio feitas durante os encontros, fontes para o processo de análise acerca da problemática de pesquisa. No movimento de exposição da análise, organizamos o trabalho em três isolados denominados planejamento, coletividade e professor em atividade. Cada um desses isolados foram discutidos na forma de episódios e constituídos de um conjunto de cenas. Como resultados, constatamos, por meio da análise dos dados coletados que os sujeitos compreenderam a coletividade e o planejamento compartilhado como elementos representativos para a organização do ensino em sala de aula por intermédio dos encontros coletivos semanais. Nessa perspectiva, podemos destacar a importância destes momentos compartilhados de estágio na formação de futuros docentes como fundamentais ao processo de aprendizagem da docência.

PALAVRAS-CHAVE: Formação de professores para a Educação Básica. Licenciatura em Matemática. Estágio Curricular Supervisionado. Compartilhamento de ações. 


\section{INTRODUÇÃO}

Conta a História que nem sempre a formação de professores foi condição para o exercício da docência. Em diferentes momentos históricos fazia-se professor aquele que dominava o conteúdo a ser ensinado. No contexto brasileiro, é por meio do Decreto Lei no 1.190 de abril de 1939 que surge o curso de Pedagogia, criado inicialmente na Faculdade Nacional de Filosofia da Universidade do Brasil. Este curso tinha como função a formação de bacharéis destinados a atuar como técnicos de educação, e a formação de licenciandos aptos à docência nos cursos normais (ANDRADE; RESENDE, 2010; TANURI, 2000).

Conforme Pereira (1998 apud Santos, 2008), com a existência deste curso deu-se início a um esquema denominado " $3+1$ ", em que os três primeiros anos eram destinados às disciplinas específicas e no último ano eram abordadas as disciplinas de cunho pedagógico. Consoante o autor, as disciplinas de natureza "prática" apareceram neste período diante da organização dos cursos universitários. Segundo Andrade e Resende (2010), este esquema institui "uma nítida fragmentação entre a formação nos conteúdos específicos e a formação pedagógica" (p. 235) que ainda perdura como um 'ranço' em muitos contextos de formação de professores.

Embora as diretrizes para formação inicial de professores tenham incorporado vários elementos que intentem romper essa tradição histórica de formação, ainda é perceptível em muitos processos formativos uma compreensão de que o estágio se constitui como tempo destinado a aplicar na prática os conhecimentos adquiridos na formação, como se o futuro professor desenvolvesse a aprendizagem da docência pela justaposição de teoria e prática, no sentido de tomar os conhecimentos adquiridos na universidade e aplicá-los na escola de educação básica.

É com o Parecer CNE/CP 09/2001 que a disciplina de estágio curricular supervisionado passa a ser entendida como "uma tarefa para toda a equipe de formadores e não, apenas, para o 'supervisor de estágio'” (BRASIL, 2001, p. 23). Ademais, o parecer destaca a importância de articular teoria com a prática, na qual "a prática na matriz curricular dos cursos de formação não pode ficar reduzida a um espaço isolado, que a reduza ao estágio como algo fechado em si mesmo e desarticulado do restante do curso" (BRASIL, 2001, p. 57).

Com a Resolução no 2, do dia 1ำ de julho de 2015, são determinadas as diretrizes curriculares nacionais direcionadas para a formação inicial em nível superior e para a formação continuada. O artigo décimo terceiro, parágrafo terceiro, inciso II, apresenta o total de 400 horas dedicadas ao estágio supervisionado. Diante destas horas previstas nesta diretriz referente ao estágio, no parágrafo sexto consta ainda que o estágio seja um componente obrigatório na organização do currículo das licenciaturas. Ele se torna uma "atividade específica intrinsecamente articulada com a prática e com as demais atividades de trabalho acadêmico" (BRASIL, 2015, p. 11 e 12).

Com a Resolução no 2, do dia 10 de julho de 2015, são determinadas as diretrizes curriculares nacionais direcionadas para a formação inicial em nível superior e para a formação continuada. $\mathrm{O}$ artigo décimo terceiro, parágrafo terceiro, inciso II, apresenta o total de 400 horas dedicadas ao estágio supervisionado. Diante destas horas previstas nesta diretriz referente ao estágio, 
no parágrafo sexto consta ainda que o estágio seja um componente obrigatório na organização do currículo das licenciaturas. Ele se torna uma "atividade específica intrinsecamente articulada com a prática e com as demais atividades de trabalho acadêmico" (BRASIL, 2015, p. 11 e 12). Essa mudança na compreensão do estágio como espaço de formação e aprendizagem da docência tem conduzido à necessidade de investigar mais profundamente o estágio como campo estruturante na formação de professores. É nesse contexto que se inseriu a pesquisa base deste artigo, com a qual delineou-se a formulação de algumas questões, tais como: Quais são as atividades que o professor orientador de estágio precisa realizar perante as primeiras experiências dos estagiários? Quais são as mediações necessárias neste processo de formação do futuro professor? Estas e outras questões constituíram o ponto de partida para a problemática de investigação: No processo de organização do ensino pelo professor de estágio, como o compartilhamento de ações de estágio pode constituir-se como espaço de formação e inserção à docência de estudantes de Licenciatura em Matemática?

A pesquisa teve como objetivo investigar possibilidades de organização do ensino em situações de compartilhamento pelo professor da disciplina de estágio, que pudessem vir a contribuir para a inserção dos estudantes na docência, no contexto do estágio.

Em consonância com o objetivo de pesquisa, optou-se pelo acompanhamento das turmas de estágio 3 e 4 no curso de Licenciatura em Matemática da Universidade Tecnológica Federal do Paraná (UTFPR), câmpus Curitiba, adotando-se como instrumentos para obtenção de dados registros escritos em diário de bordo e gravações em áudio dos encontros semanais desta disciplina, nos momentos destinados ao compartilhamento das ações dos estagiários. A pesquisa se deu à luz dos pressupostos do materialismo históricodialético buscando-se captar o fenômeno em movimento no contexto desses encontros de estágio.

A seguir, apresentamos alguns aspectos da Teoria da Atividade para a organização de ensino em situações de estágio e o transcorrer da pesquisa realizada, bem como um recorte da análise desenvolvida. Em consonância com o objetivo de pesquisa, optou-se pelo acompanhamento das turmas de estágio 3 e 4 no curso de Licenciatura em Matemática da Universidade Tecnológica Federal do Paraná (UTFPR), câmpus Curitiba, adotando-se como instrumentos para obtenção de dados registros escritos em diário de bordo e gravações em áudio dos encontros semanais desta disciplina, nos momentos destinados ao compartilhamento das ações dos estagiários. A pesquisa se deu à luz dos pressupostos do materialismo histórico-dialético buscando-se captar o fenômeno em movimento no contexto desses encontros de estágio.

A seguir, apresentamos alguns aspectos da Teoria da Atividade para a organização de ensino em situações de estágio e o transcorrer da pesquisa realizada, bem como um recorte da análise desenvolvida.

\section{CONTRIBUIÇÕES DA TEORIA DA ATIVIDADE PARA A ORGANIZAÇÃO DE ENSINO EM SITUAÇÕES DE ESTÁGIO}

Na pesquisa desenvolvida abordamos contribuições da Teoria da Atividade para a organização do ensino no contexto dos estágios nas licenciaturas. Apresentamos temas relevantes à luz do referencial, tais como: o planejamento da atividade de 
ensino e a coletividade no processo formativo e nas ações de ensino para a aprendizagem da docência, para que pudessem dar suporte na posterior análise dos dados.

Assim como Silva e Cedro (2015), almejamos compreender o planejamento como uma "atividade conscienciosa e sistemática, centrada na aprendizagem ou no estudo, mediada intencionalmente pelo professor, como elemento de orientação de suas decisões" (SILVA; CEDRO, 2015, p. 193).

Nesse sentido, o planejamento é algo que inicialmente é apresentado como "atividade coletiva (social), depois, em forma de comunicação entre as pessoas; em seguida, como atividade individual e consciência individual" (SILVA; CEDRO, 2015, p. 194).

Segundo Lopes (2004), o planejamento compartilhado assume o papel de "organizador da atividade docente" (LOPES, 2004, p. 131). Este ato de planejar compartilhado se tornará atividade no momento em que os projetos individuais se confluem ao redor de um mesmo objetivo, e os docentes em formação passam a assumir a existência de uma necessidade que é comum para todos: a organização do ensino. Desse modo, tornam-se sujeitos inseridos numa díade: "a relação atividade-ação que possui como condição a mesma que Leontiev coloca para a atividade - coincidência entre motivo e objeto" (SILVA, 2014, p. 86).

Neste contexto da formação de professores, em específico o estágio, faz-se necessário organizar o ensino de modo que o futuro professor seja "colocado em atividade". Em vista disso, surge a proposta de situações desencadeadas por "necessidades e motivos e, portanto, geradoras de ações e operações vinculadas ao objeto, ao motivo da atividade, que, portanto, deem conta de tais necessidades" (RIBEIRO, 2011, p. 48).

Dessa maneira, para um indivíduo se encontrar em atividade é necessário que o objetivo de sua ação coincida com o motivo de sua atividade. De fato, a diferença de uma atividade para outra é o seu objeto, o seu motivo real, de modo que "ambos necessariamente devem coincidir dentro da atividade" (MORETTI; MOURA, 2011, p. 439). Leontiev ([19-], p. 15 apud MORETTI; MOURA, 2011) afirma que:

\footnotetext{
uma atividade só se constitui como tal se partir de uma necessidade. No entanto, a necessidade não é entendida por ele como o motivo da atividade. A necessidade que deu origem à atividade objetiva-se materialmente no motivo, dentro das condições consideradas, e é este que estimula a atividade, o que lhe confere direção (p. 439).
}

O fator que desencadeia a atividade, portanto, é a necessidade, e esta motiva o indivíduo a ter objetivos e a efetuar ações. Segundo Sforni (2004), "nem todo processo é uma atividade, mas somente aquele que é movido por uma necessidade" (SFORNI, 2004, p. 97).

Silva (2014) afirma que existe a necessidade de elaborar oportunidades de "aprendizagem/planejamento/organização do ensino". De fato, faz-se necessário compreender a atividade pedagógica como atividades coletivas, de forma a abranger os futuros docentes em ações que favoreçam o entendimento da complexidade do ato formador e dos processos de aprendizagem sobre a profissão (MOURA, 2011). 
Moretti (2007) assegura que, por meio da organização coletiva de suas ações, os docentes atribuem novos sentidos às próprias ações, à mediação e à escolha de instrumentos, de modo a se apropriar das formas de realização colaborativa da atividade de ensino.

Ainda referente à coletividade, encontramos em Rubtsov (1996) a ideia de que o sujeito se desenvolve do coletivo para o individual e que a aprendizagem se dá na perspectiva do coletivo como um caminho de apropriação do conhecimento. Para o autor,

[...] as pesquisas dos psicólogos mostraram que a aptidão para a aprendizagem é, na verdade, resultado de uma determinada interiorização, de maneira que a atividade de aprendizagem se apresenta, essencialmente, sob a forma de uma atividade realizada em comum (RUBTSOV, 1996, p. 134).

Ademais, o autor destaca que uma atividade somente poderá ser caracterizada como uma atividade coletiva se contiver alguns destes elementos: "a repartição das ações e das operações iniciais da atividade, troca de modos de ação, compreensão mútua, a comunicação, o planejamento das ações individuais, a reflexão" (RUBTSOV, 1996, p. 136).

Por intermédio de momentos de compartilhamento das ações, podemos propiciar aos sujeitos a oportunidade de desenvolver as primeiras formas específicas de cooperação, que permitirá a ele "atingir um nível adequado nas ações cognitivas por meio da apropriação e da conscientização do processo significativo da produção coletiva do conhecimento científico" (CEDRO, 2008, p. 146).

De fato, podemos perceber que a aprendizagem da docência é compreendida na relação intrínseca entre "o ensino, atividade principal do professor e a aprendizagem, atividade compartilhada com os estudantes" (CEDRO, 2008, p. 209). Isto implica que é por meio da atividade de ensino que o professor determina os motivos para que os estudantes possam se mobilizar rumo à aprendizagem.

Desta maneira, conhecendo as inúmeras possibilidades de orientação que podem ser exercidas pelo professor orientador do estágio com os seus licenciandos, destacamos o compartilhamento das ações dentro da disciplina de estágio em um ambiente envolvendo os professores e alunos.

Araujo (2009), nesse espaço de compartilhamento das ações dentro do estágio, expõe que os docentes que já atuam "compartilham significados sociais do ser e estar professor em condições objetivas de trabalho" (ARAUJO, 2009, p. 10). Por meio destas propostas de intervenção, os estudantes podem se constituir como "parceiros com mais experiência" (ARAUJO, 2009, p. 10).

Nesse sentido, a compreensão da organização do ensino pelo professor formador e, por conseguinte, o entendimento do compartilhamento das ações num espaço coletivo dentro do contexto do estágio, poderá possibilitar ao futuro docente a oportunidade de refletir e agir perante às novas exigências para atuar neste novo cenário de sala de aula, onde o professor precisa desenvolver seus conhecimentos bem como suas competências adquiridas ao longo de um curso de licenciatura. 


\section{O CAMINHO PERCORRIDO NA PESQUISA}

Na busca por respostas à problemática da pesquisa, o trabalho pautou-se em elementos da Teoria da Atividade, tendo como fundamento para os encaminhamentos metodológicos o método histórico-dialético, de modo que a pesquisa colocasse em relação "a teoria em questão e o método filosófico e investigativo que Ihes sustenta" (CEDRO; NASCIMENTO, 2017, p. 14). Nesse sentido, segundo Cedro e Nascimento (2017), é fundamental que o fenômeno em estudo seja apresentado de modo que permita ser apreendido em sua totalidade.

Para Ribeiro (2011), a escolha deste método se justifica pela possibilidade de estudo dos fenômenos que envolvem a formação do futuro docente na sua complexidade e historicidade, tendo foco nos diferentes elementos que compõem a totalidade da atividade do professor.

De acordo com Rigon, Asbahr e Moretti (2010), como procedimento metodológico intenta-se criar condições de pesquisa que permitam analisar o processo de desenvolvimento do objeto em estudo, exigindo, assim, acompanhamento das ações realizadas pelos sujeitos envolvidos com a pesquisa e também a permanência prolongada em campo durante o período de tempo que possibilitar compreender o fenômeno a ser estudado, no qual se situam os encontros de compartilhamento das ações de estágio.

Para isso, propusemos percorrer um caminho metodológico que possibilitasse o acompanhamento do curso de Licenciatura em Matemática, mais especificamente o desenvolvimento das disciplinas de estágio 3 e 4 oferecidas no curso, ofertadas durante o ano de 2016. Justifica-se a opção da escolha do campo de pesquisa - a Universidade Tecnológica Federal do Paraná - pelo fato da proximidade com a instituição de ensino e pela possibilidade de acompanhamento do fenômeno por um tempo prolongado e em situação coletiva.

Sabemos que a disciplina de estágio abrange os espaços da universidade e da escola e tendo conhecimento das inúmeras possibilidades de orientação que podem ser exercidas pelo professor orientador do estágio com os seus licenciandos, o foco principal centrou-se nos encontros semanais coletivos da disciplina.

Ao longo do ano letivo de 2016, durante o primeiro e segundo semestre, realizou-se o acompanhamento dos encontros de compartilhamento das ações de estágio da turma de Estágio 3 e do Estágio 4 do curso de Licenciatura em Matemática da Universidade Tecnológica Federal do Paraná (UTFPR). Nos horários previstos, as duas turmas encontravam-se para discutir os planos de aula planejados e desenvolvidos nas regências, bem como seus anseios, dúvidas, perspectivas e resultados apresentados nas aulas nas escolas.

A pesquisa realizada contou com 12 estudantes de Licenciatura em Matemática matriculados nos estágios 3 e 4 (denominados $A 1, A 2, A 3, .$. ), duas professoras orientadoras da disciplina (P1 e P2) e uma professora convidada a orientar um grupo de estudantes de estágio. 


\section{O PROCESSO DE ANÁLISE}

Para darmos conta da exposição dos dados captados, conduzindo assim o processo de análise em sua totalidade, adotou-se o conceito de isolado. Esse conceito apresentou-se fundamental na pesquisa como um modo de exposição do fenômeno a ser analisado. Deve-se destacar, porém, que não existe "uma relação hierárquica entre os isolados, tanto do ponto de vista temporal, quanto qualitativo, mas, sim, uma relação dialética entre eles" (ARAUJO, 2003, p. 67).

Para a organização e discussão dos dados da pesquisa, ao adotarmos o conceito de isolado como um modo de expor o fenômeno em estudo, partimos de episódios representativos do movimento formativo em situações de compartilhamento de ações de estágio. Organizamos os episódios de modo que possibilitem revelar potencialidades do movimento de compartilhamento das ações de estágio para a formação docente.

Apoiados na ideia de episódios e com base em sucessivas leituras dos dados captados, selecionamos trechos das gravações em situação coletiva que acreditamos ser mais significativos e expressivos, e que proporcionassem algumas respostas às nossas inquietações diante do objeto de pesquisa.

Segundo Moraes (2008), "o conteúdo dos episódios será apresentado por um conjunto de cenas escolhidas dentre os dados levantados com o objetivo de revelar as ações no processo formativo" (MORAES, 2008, p. 136). Desse modo, busca-se revelar as diversas determinações e as relações essenciais que possam favorecer a compreensão do fenômeno para além da aparência, do imediato (ARAUJO E MORAES, 2017).

Os episódios foram constituídos por um conjunto de trechos, denominados cenas, selecionados durante as gravações das aulas de estágio no ano letivo de 2016 e que revelam indícios de como as situações de compartilhamento das vivências de estágio podem se constituir significativas ao processo formativo. Segundo Ribeiro (2011), as cenas são "constituídas de registros orais ou escritos, nos quais os futuros professores evidenciam indícios desse movimento formativo de aprendizagem da docência" (RIBEIRO, 2011, p. 100).

Neste movimento de análise, para Araujo e Moraes (2017) se faz necessário conversar com a teoria, e não sobre a teoria. Desse modo, organizamos este trabalho em três isolados, sendo esses entendidos como nossas "unidades de análise" que permitem explicitar as manifestações do fenômeno em estudo. Cada um dos isolados foi discutido sob a forma de episódios, constituídos de um conjunto de cenas.

Para a análise, com base nos dados apreendidos no decorrer da pesquisa, organizou-se os isolados de análise. Esses isolados são discutidos sob a forma de episódios, compostos por cenas, conforme Araujo (2003), Moraes (2008) e Ribeiro (2011). Segundo Rigon (2011), elaboração do dado, uma vez que para a escolha e o recorte do mesmo há uma intenção de que ele represente algo valioso para o processo de análise. De alguma forma, o episódio também representa uma primeira organização dos dados brutos, uma vez que eles não estão prontos pelo simples ato da transcrição (RIGON, 2011, p. 163). 
Deste modo, na exposição dos episódios, buscamos identificar momentos significativos do compartilhamento das ações de estágio que, de certa forma, evidenciam a figura do professor da disciplina de estágio como contribuinte para a formação e inserção dos alunos no estágio da docência. E que, portanto, revelam elementos de organização do ensino que favorecem a formação dos futuros professores em situação de estágio. No processo de análise, constituiu-se o seguinte quadro:

QUADRO 1 - SÍNTESE DE ANÁLISE

\begin{tabular}{|c|c|c|}
\hline Isolados & Episódios & Cenas \\
\hline \multirow{2}{*}{ Planejamento } & \multirow{2}{*}{$\begin{array}{c}\text { Episódio 1: A } \\
\text { importância do } \\
\text { compartilhamento dos } \\
\text { planejamentos }\end{array}$} & $\begin{array}{l}\text { Cena 1: Compreensões das } \\
\text { professoras acerca do } \\
\text { planejamento }\end{array}$ \\
\hline & & $\begin{array}{c}\text { Cena 2: Percepção acerca da } \\
\text { importância do planejamento } \\
\text { de aula. }\end{array}$ \\
\hline \multirow[b]{2}{*}{ Coletividade } & \multirow{2}{*}{$\begin{array}{l}\text { Episódio 2: O espaço } \\
\text { coletivo como } \\
\text { contribuinte na } \\
\text { formação do sujeito }\end{array}$} & Cena 1: O caso do aluno A4 \\
\hline & & $\begin{array}{l}\text { Cena 2: O compartilhamento } \\
\text { das ações no espaço coletivo }\end{array}$ \\
\hline \multirow{3}{*}{ Professor em atividade } & \multirow{3}{*}{$\begin{array}{l}\text { Episódio 3: Sentido e } \\
\text { Significado do ser } \\
\text { Professor }\end{array}$} & $\begin{array}{l}\text { Cena 1: Percepção inicial do } \\
\text { aluno e da professora }\end{array}$ \\
\hline & & $\begin{array}{l}\text { Cena 2: Atribuição de novos } \\
\text { sentidos do ser professor }\end{array}$ \\
\hline & & $\begin{array}{l}\text { Cena 3: Novos significados da } \\
\text { prática docente atribuídos } \\
\text { pelos alunos estagiários }\end{array}$ \\
\hline
\end{tabular}

Fonte: Corso (2018, p. 63 e 64).

Desta forma, apresentado o quadro de síntese da análise do trabalho, iremos mostrar uma síntese de análise de todo o material coletado. Fizemos recortes dos momentos de compartilhamento de estágio que pudessem revelar como esse espaço pode constituir-se formativo no estágio, entendendo que os sujeitos desenvolvem esse movimento do coletivo para o individual.

Para ilustrar o movimento de análise, o recorte do episódio 1 , referente à cena 2, nos apresenta a percepção acerca da importância do planejamento de aula. De modo bem particular, ressaltamos a figura do professor de estágio como incentivador da construção e do compartilhamento do planejamento nos encontros semanais.

No início da aula do segundo semestre de 2016, o aluno A1 compartilhou com a turma de estágio sobre a sua regência com o nono ano referente ao conteúdo do Teorema de Tales. Segundo o seu relato, retirado do diário de bordo da autora, o objetivo desta aula, em específico, era fazer com que os estudantes compreendessem o Teorema de Tales e pudessem aplicá-lo na resolução dos exercícios. A ideia inicial era mostrar visualmente aos alunos por meio de um software matemático que combina, por exemplo, a geometria e suas representações no gráfico, denominado Geogebra, porém não havia suporte para isto. 
Sendo assim, A1 elaborou uma atividade para introduzir o conteúdo do Teorema de Tales para que os estudantes pudessem verificar e analisar a construção das retas paralelas. Após isto, pode enunciar matematicamente o Teorema.

Depois de apresentar em detalhes a sequência de sua aula, houve o seguinte diálogo:

P1: Eu lembro da sua primeira aula que você apresentou no estágio 3 ainda, não sei se você lembra.

A1: Eu lembro (risos).

P1: Eu vou dizer porque eu lembro, porque está muito diferente (...) ele tinha perguntado assim: como é que eu passo para o aluno um problema que tenha a questão da área que ele precisava resolver a raiz sem ter identificado o que era raiz. Era essa a pergunta. Então qual era a ideia do aluno A1? Que ele primeiro tinha que explicar conceitualmente, matematicamente o que era raiz quadrada por definição e que depois aplicar (...) que era difícil dar uma situação que o aluno pudesse tentar resolver mesmo que ele não tivesse o conceito de raiz quadrada. Aí eu lembro que eu falei: que o aluno tem que primeiro pensar a respeito e depois você formaliza (...)

A1: E agora a professora mostrou como fazia e agora eu faço totalmente o inverso (RA, 18/11/2017).

No decorrer do ano de 2016, este estudante esteve matriculado nos Estágios 3 e 4 e teve a oportunidade de se fazer presente nesta forma de compartilhamento das ações de estágio proposta pela disciplina de estágio. É justamente neste relato da professora que se permite identificar evidências de mudança por parte do estagiário. Podemos analisar a percepção do aluno sobre a existência de um outro modo de realizar o planejamento de um determinado conteúdo.

Por meio deste modo de compartilhamento das ações de estágio, a professora pode perceber a evolução deste aluno. Caso não houvesse estes momentos para discutir, refletir e analisar as ações de estágio, o aluno iria continuar realizando o mesmo planejamento e teria a mesma concepção acerca do modo de organizar a exposição de um conteúdo matemático.

A seguir, apresenta-se uma das cenas constitutivas do segundo episódio, em que se revela o isolado "coletividade". Esta cena retrata um dos encontros de estágio da turma do primeiro semestre, em junho de 2016. Estavam presentes as professoras orientadoras e os alunos A1, A2, A3 e A5.

No início desta aula de estágio a aluna A2 mencionou sua última aula de regência com a turma do nono ano, que tratava o conteúdo de equação do segundo grau completa utilizando o método de completar quadrado. Segundo o seu relato, a turma estava bastante agitada por ser a última aula daquele dia, porém, quando iniciou a explicação, os alunos ficaram um pouco assustados e logo silenciaram. No meio da aula, todavia, houve interrupção da diretora que precisava dar um recado para a turma e, deste modo, não foi possível finalizar o conteúdo em sala. Como esta era a última aula de estágio nesta turma, foi necessário que o professor da classe retomasse novamente o conteúdo com os 
alunos em outro dia da semana. Diante deste relato retirado do registro de áudio no encontro de estágio, houve o seguinte questionamento:

A3: Como é que você explicou? Se explicou algebricamente ou usou a geometria; não sei assim, eu estava pensando agora.

A2: Eu comecei a fazer sentido com o quadrado e daí fui fazer algebricamente, mas eles ainda ficaram bem-confusos.

A3: Uhum entendi. É que eu fiquei pensando como é que eu daria uma aula assim? Nunca pensei em dar uma aula assim. Dá para fazer com completar quadrado né?

P1: Sim, é o ideal, começar com isso e depois fazer com a parte algébrica

P2: Fazer sentido para eles, o visualmente, isso é o importante (RA, $3 / 6 / 2016)$.

Este episódio nos retrata a importância do coletivo nestes espaços de compartilhamento das ações de estágio. Por meio da partilha da aluna A2, a aluna $A 3$, já se posicionando como futura professora de uma sala de aula e talvez em um futuro breve tendo de explicar este conteúdo, questiona-se como deveria explicar.

Ao observar a ação da sua colega, houve então uma troca de experiências, quando agregou novos significados da prática docente da aluna A3. Houve também o destaque das duas professoras presentes, que concordaram com a maneira de abordar aquele assunto, além do comentário destacando a importância de mostrar o "visual" tão importante nos conteúdos matemáticos, que os torna mais acessível de compreender.

Para Fraga (2013), estes momentos de rever a prática no grupo objetivam oferecer ao estagiário o olhar sobre o ensino, tendo a presença de professores com mais experiência, favorecendo "uma (re)construção dos sentidos e significados de aprender e ensinar" (FRAGA, 2013, p. 83). A partir do diálogo proporcionado por estes momentos de coletividade, possibilitou-se criar condições para o aprendizado por parte das futuras professoras, agregando novos significados na sua formação docente.

No terceiro isolado "professor em atividade", fizemos um recorte do episódio 3, cena 3, que tem como objetivo evidenciar de que modo a função exercida pelo professor da disciplina nestes momentos do compartilhamento contribui para a formação do docente de modo a atribuir novos sentidos do ser professor.

No dia 18 de março tive o primeiro contato com os alunos do primeiro semestre, quando foram apresentados os objetivos desta pesquisa e questionado os alunos e professores se estavam de acordo com ela. A seguir, apresento um relato da opinião dos alunos sobre a pesquisa:

A3: Eu também acho bem legal o tema por que eu acho bem importante para a nossa formação porque é da universidade para o mercado de trabalho. O estágio faz com que a gente realmente saiba que a gente escolheu é aquilo, ou você gosta ou você chega lá e diz não quero ser professora. 
A1: E daí chega lá no terceiro ano e descobre que você não quer ser professora

A3: Mas você pode seguir outra coisa na área de matemática, na parte pura, aplicada, mas se você quer ser professor você vai gostar ou se não pensava em ser, o estágio vai te ajudar (RA, 18/3/2016).

Durante as falas dos alunos A1 e A3, pode-se perceber que são nos momentos de estágio que surge a dúvida de "ser ou não ser professor" de matemática, em razão das dificuldades enfrentadas em sala, ou até mesmo na quebra de alguns paradigmas e expectativas já criadas pelos próprios alunos de estágio. Deste modo, também podemos destacar que é neste período de estágio que o futuro professor vai atribuindo novos sentidos a sua própria prática docente.

Segundo Dias e Souza (2017),

à medida que, no processo interativo teoria-prática, o professor transforma e se transforma pelo movimento de apropriação dos conhecimentos presentes nas relações de ensino-aprendizagem, também resignifica sua atividade de ensino e desenvolve sua consciência profissional (DIAS E SOUZA, 2017, p. 197).

Ao propor este modo de compartilhar as ações de estágio por meio dos encontros coletivos, podemos propiciar aos alunos um modo de compreender sua atividade em sala de aula e desenvolver sua consciência quanto à atividade profissional docente.

É nesta fase de tomada de consciência da sua futura profissão que a figura do professor de estágio se destaca. Por meio das atividades compartilhadas dentro dos encontros coletivos semanais, o professor de estágio pode acompanhar o processo de formação do futuro professor.

\section{CONSIDERAÇÕES FINAIS}

No contexto da pesquisa, cumpre-nos destacar, conforme Silva (2014), que nos detemos a dar ênfase ao compartilhamento por apenas um motivo: "o estágio supervisionado não é uma ocasião de aprendizagem solitária" (SILVA, 2014 , p. 73). Nesse sentido, quando nos propomos a investigar possibilidades de organização do ensino em situações de compartilhamento, acreditamos que era nesses momentos coletivos dos encontros semanais, na interação entre aluno e professor, que, de fato, criar-se-iam mais condições de aprendizagem do futuro docente.

Um dos resultados obtidos por meio da organização dos isolados e elaboração dos episódios foi a existência de um modo de compartilhar as ações de estágio dentro do espaço de formação de professores, em que se valorizam as trocas, o espaço coletivo como espaço formador e o planejamento compartilhado, de modo a propiciar reflexões sobre a prática do futuro docente.

No isolado planejamento destacou-se a questão de acrescentar experiência aos estagiários, da importância do professor que acompanha o estágio e do aluno ter outras visões sobre o planejamento. Em coletividade, ressalta-se a questão do compartilhamento das experiências e dos novos/outros olhares que esse modo 
de organização do ensino favorece e potencializa em sala de aula, como também, a importância da organização do ensino pelo professor da disciplina de estágio, na direção da constituição do professor em atividade, que se vê diante de necessidades e motivos de formar-se e formar.

Uma das principais conclusões centra-se no entendimento de que é possível construir um espaço de formação que contribua para a inserção dos estudantes à docência, no contexto do estágio em situações de coletividade, para além do cumprimento da carga horária prevista na resolução vigente (BRASIL, 2015), em que se prevê 400 horas de estágio na formação inicial.

Durante o acompanhamento das turmas de estágio ao longo do ano de 2016, pudemos identificar uma prática de estágio na qual o compartilhamento das ações de estágio estava sempre em primeiro plano. O contato entre professor e aluno era sempre direto, proporcionando trocas de experiências bem como o crescimento profissional do futuro docente.

Nesse sentido, destacamos os encontros semanais como espaço formativo tanto para os professores quanto para os estagiários. A partir da intencionalidade em se investigar um espaço em que se pudesse compartilhar as ações de estágios, os sujeitos puderam percebem a coletividade e o planejamento compartilhado como elementos centrais para a organização do ensino em sala de aula.

Ao limitarmos a nossa pesquisa apenas em um campo específico, ou seja, na Universidade Tecnológica Federal do Paraná, com alunos e professores da disciplina de estágio, encontramos determinados resultados. Se mudássemos de cenário, porém, poderíamos encontrar outros resultados, contudo esperamos que este trabalho tenha contribuído para a formação de novos professores e possibilitado novos olhares aos leitores acerca do modo como se dá a organização do ensino na disciplina de estágio nas licenciaturas, sendo essa entendida como um momento determinante na formação inicial docente. 


\title{
The sharing of internship actions as space for initial formation teaching
}

\begin{abstract}
The following article presents the master's research results developed in the area of Mathematical Education, particularly about the internship on initial formation of Math teachers. Based on the Activity Theory, the investigation was developed by the way of camp researching with accompaniment situations in classes of Curricular Supervised Internship in a Mathematics degree, focusing on the moments of shared internship responsibilities. In this scenario it was investigated possibilities to organize the teaching by the teacher of the discipline of the internship that could favor the insertion of students in lecturing in the context of the curricular supervised internship. The research occurred by the way of the historic-dialectic materialism method. The data captioning process was done by the way of logbook, observations, and audio recordings made during the encounters, sources for the process of analysis regarding the problematic of the research. In the movement of the analysis' exposure, we organized the project in three isolates known as planning, collectivity and teacher in activity. Each of these isolates were discussed in the form of episodes and constituted of a set of scenes. As results, we noticed, by the collected data analysis that the characters comprehended the collectivity and the shared planning as representative elements for the organization of the teaching in class through weekly collective encounters. In this perspective, we can point the importance of these shared moments of internship in the formation of future teachers as fundamental to the process of learning of the teachers.
\end{abstract}

KEYWORDS: Teacher training to the elementary education. Degree in mathematics. Curricular supervised internship. Sharing of actions. 


\section{REFERÊNCIAS}

ANDRADE, C. R.; RESENDE, M. R. Aspectos legais do estágio na formação de professores: uma retrospectiva histórica. Educação em Perspectiva, Viçosa, v. 1, n. 2, p. 230-252, jul./dez.

ARAUJO, E. S. Da formação e do formar-se: a atividade de aprendizagem docente em uma escola pública. 2003. Tese (Doutorado em Educação) Faculdade de Educação, Universidade de São Paulo, São Paulo, 2003.

ARAUJO, Elaine Sampaio. Mediação e aprendizagem docente. CONGRESSO NACIONAL DE PSICOLOGÍA ESCOLAR E EDUCATIONAL, 9. São Paulo: ABRAPPE, 2009.

ARAUJO, E. S. MORAES, S. P. G. Dos princípios da pesquisa em educação como atividade. In: MOURA, M. O. (Org.). Educação escolar e pesquisa na teoria histórico-cultural. São Paulo: Loyola, 2017.

BRASIL. Parecer 9/2001. Diretrizes Curriculares Nacionais para a Formação de Professores da Educação Básica, em nível superior, curso de licenciatura, de graduação plena. Disponível em:

http://portal.mec.gov.br/cne/arquivos/pdf/009.pdf. Acesso em: 22 jun. 2019.

BRASIL. CNE/CP. Resolução 02, de 01 de julho de 2015. Define as Diretrizes Curriculares Nacionais para a formação inicial em nível superior (cursos de licenciatura, cursos de formação pedagógica para graduados e cursos de segunda licenciatura) e para a formação continuada. Disponível em: http://pronacampo.mec.gov.br/images/pdf/res_cne_cp_02_03072015.pdf. Acesso em: 22 maio. 2019.

CEDRO, W. L. O motivo e a atividade de aprendizagem do professor de matemática: uma perspectiva histórico-cultural. 2008. Tese (Doutorado em Educação) - Faculdade de Educação, Universidade de São Paulo, São Paulo, SP, 2008.

CEDRO, W. L. NASCIMENTO, C. P. Dos métodos e das metodologias em pesquisas educacionais na teoria histórico-cultural. In: MOURA, M. O. (Org.). Educação escolar e pesquisa na teoria histórico-cultural. São Paulo: Loyola, 2017.

CORSO, B. O compartilhamento de ações de estágio como espaço de formação: contribuições da Teoria da Atividade. 2018. Dissertação (Mestrado em Educação em Ciências e Matemática) - Universidade Federal do Paraná, Curitiba, 2018. 
FRAGA, L. P. Futuros professores e a organização do ensino: o clube de matemática como espaço de aprendizagem da docência. 2013. Dissertação (Mestrado em Educação) - Universidade de Santa Maria, Santa Maria, 2013.

LOPES, A. R. L. V. A aprendizagem docente no estágio compartilhado. 2004. Tese (Doutorado em Educação) - Universidade de São Paulo, São Paulo, 2004.

MORAES, S. P. G. Avaliação do Processo de Ensino e Aprendizagem em Matemática: Contribuições da teoria história-cultural. 2008. Tese (Doutorado em Educação) - Faculdade de Educação, Universidade de São Paulo, São Paulo, 2008 .

MORETTI, Vanessa Dias. Professores de Matemática em Atividade de Ensino: uma perspectiva histórico-cultural para a formação docente. 2007. Tese (Doutorado em Educação) - Faculdade de Educação, Universidade de São Paulo, São Paulo, SP, 2007.

MORETTI, V. D.; MOURA, M. O. Professores de matemática em atividade de ensino: contribuições da perspectiva histórico-cultural para a formação docente. Ciência \& Educação, v. 17, n. 2, p. 435-450, 2011.

MOURA, M. O. A aprendizagem inicial do professor em atividade de ensino. In: LOPES, A. R. L. V.; TREVISOL, M. T. C.; PEREIRA, P. S. (Org.). Formação de professores em diferentes espaços e contextos. Campo Grande, MS: Ed. UFMS, 2011.

RIBEIRO, F. D. A aprendizagem da docência na prática de ensino e no estágio: contribuições da teoria da atividade. 2011. Tese (Doutorado em Educação) Faculdade de Educação, Universidade de São Paulo, São Paulo, SP, 2011.

RIGON, A. J. Ser sujeito na atividade de ensino e aprendizagem. 2011. Tese (Doutorado em Educação) - Faculdade de Educação, Universidade de São Paulo, São Paulo, SP, 2011.

RIGON, A.J.; ASBAHR, F.S.F.; MORETTI, V.D. Sobre o processo de humanização. In: MOURA, M.O. (coord.). A atividade pedagógica na teoria histórico-cultural. Brasília: Líber, 2010.

RUBTSOV, V. A atividade de aprendizagem e os problemas referentes à formação do pensamento teórico dos escolares. In: GARNIER, C.; BEDNARZ, N.; ULANOVSKAYA, I. Após Vygotsky e Piaget: perspectivas social e construtivista. Escolas russa e ocidental. Tradução Eunice Gruman. Porto Alegre: Artes Médicas, 1996. 
SANTOS, A. A. P. O estágio como espaço de elaboração dos saberes docente e a formação do professor. 2008. 170f. Dissertação (Programa de Pós-Graduação em Educação da Faculdade de Ciências e Tecnologia) - Universidade Estadual Paulista, Presidente Prudente, 2008.

SILVA, M. M. CEDRO, Wellington Lima. Estágio Supervisionado e Planejamento Compartilhado: Possibilidades da Organização do Ensino de Professores de Matemática em Formação. Educ. Matem. Pesq., São Paulo, v. 17, n. 2, p. 190215, 2015.

SILVA, M. M. Estágio Supervisionado: o planejamento compartilhado como organizador da atividade docente. 2014. Dissertação (Mestrado em Educação Ciências e Matemática) - Universidade Federal de Goiás, Goiânia, 2014.

SFORNI, M. S. de F. Aprendizagem conceitual e organização do ensino: contribuições da teoria da atividade. 1. ed. Araraquara: JM Editora, 2004.

TANURI, L. M. História da formação de professores. Revista Brasileira de Educação, n. 14, p. 61-88, maio/ago. 2000.

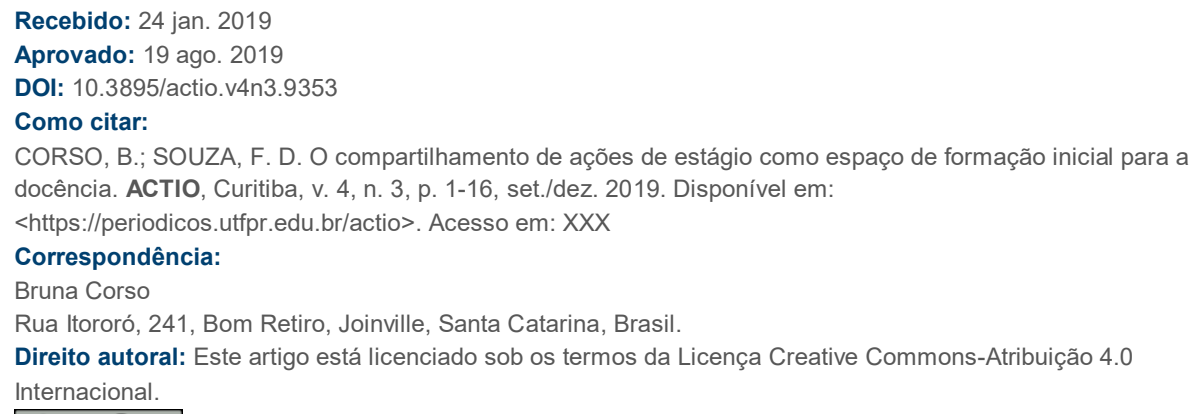

